\title{
ICT Infrastructure Resources and Practices in University of Hyderabad
}

\author{
Machunwangliu Kamei \\ Communication Department SN School, University of Hyderabad \\ Hyderabad, India
}

\begin{abstract}
The paper looks at ICT infrastructure Resources in University of Hyderabad (UOH), India. It covers responses on five sets of technologies viz. High Performance Computing, Cyber infrastructure applications and tools, Data storage management and resources, advanced network infrastructure resources and Resources for collaboration within virtual communities. The paper also investigates the level of Information Communication Technologies ICT use for educational purposes by students. The paper will contribute to the body of knowledge regarding the level of ICT practices and also, concerning the importance of students' attitudes towards the use of ICT for educational purposes. The data for the study were collected through the use of quantitative and qualitative data. The findings of the study, which were obtained by analyzing the data collected from the students, revealed that, students had a low level of ICT use for educational purpose, but held positive attitudes towards the use of ICT. The findings suggest that ICTs use for educational purposes should be given greater consideration than it currently receives. In general, the results were consistent with those previously reported in studies related to the use of ICT in the educational settings.
\end{abstract}

\section{Introduction}

Learning space is expanding creating new geographies of learning. Students now feel that learning is not limited to classroom; their learning has gone beyond that through Information Communication Technologies (ICT). Higher education institutions are not only producing and supporting technological innovations but are at the same time intensive users and subject to the limitations of ICT. The ICT revolution is already having significant impacts on students' learning processes (e.g. through the availability of virtual learning environments and new sources of information) challenging both students and teachers to re-assess their conceptions about learning and instruction [1].
The University of Hyderabad (UOH), one of the major institutions of higher education in India is largely devoted to postgraduate studies. Founded in 1974, UOH has emerged as a leading centre of teaching and research.

\section{ICT infrastructure Resources}

In University of Hyderabad, research and teaching are both primary missions, and they are considered equally important for faculty and institutional success. University of Hyderabad has an officially designated Centre for Knowledge Innovation and Culture Studies. The institution has an advisory body that deals primarily with ICT issues related to research, teaching and learning. The central ICT organization has a distinct unit with the explicit mission of supporting faculty, students, or other researchers with their research needs.

\subsection{High-Performance Computing}

High-performance computing resources at the institution are used often by many personnel. Researchers at the institution obtain access to highperformance computing resources in each of these ways:

- Use other campus resources to a small extent

- Use resources available to them through collaboration/s with other higher-education institution/s to a large extent

- Use resources available to them through governmental or private source/s, their own resources or those of their lab/s and campus central ICT resources to a moderate extent

High-performance computing resources used by researchers at the institution are funded to a moderate extent by Research funds awarded to the researcher or lab and other campus funding and to a large extent by Campus central ICT organization funds.

Level of importance of high-performance computing at the institution can be seen maximum in 
the case of Teaching and learning and to a moderate extent in the case of research in science and engineering and creative activities such as arts, music, etc.

Senior-most ICT leader has detailed knowledge about resources available to researchers. The institution has documented inventory of the highperformance computing resources used for research for all high-performance computing resources.

For the institution's research activities, the overall importance of high-performance computing in the next three years will see minor increase and a moderate increase in teaching and learning activities.

\subsection{Cyber infrastructure Applications and Tools}

This section deals with general cyber infrastructure/e-Science/e-Research applications and tools that support research but are not specific to a particular discipline. These include software for simulation, parallelization, visualization, job scheduling, data mining, statistical analysis, and so forth, but not specific sequencing, chemical analysis, or other disciplinary applications. Cyber infrastructure applications and tools at University of Hyderabad are used often by a few personnel. Researchers at the institution obtain access to cyber infrastructure applications and tools in each of these ways:

- Use their own resources or those of their lab/s to a large extent

- Use resources available to them through governmental or private source/s to a moderate extent

- Use campus central IT resources, Use other campus resources, Use resources available to them through collaboration/s with other higher education institution/s to a small extent

Cyber infrastructure applications and tools used by researchers at the institution are funded to a moderate extent by Research funds awarded to the researcher or lab, Funds awarded to the institution not specifically for the researcher or lab, Other campus funding. To a small extent by funds made available through collaboration/s with other highereducation institution/s; and a large extent by Campus central IT organization funds.

The following are the level of importance of cyber infrastructure applications and tools at the institution:

- Research in science and engineering moderate importance

- Research in other disciplines - minor importance

- Creative activities such as arts, music, etc. moderate importance
- Teaching and learning - minor importance

The senior-most ICT leader has a sound overall knowledge about the research use of cyber infrastructure applications and tools at the institution and has the ability to obtain information about the research use of cyber infrastructure applications and tools at the institution. The institution has documented inventory of the cyber infrastructure applications and tools used for research for all cyber infrastructure applications and tools.

The following would most help the central ICT organization support more effective research use of cyber infrastructure applications and tools computing resources:

- Increased funding for central ICT infrastructure

- Increased funding for central ICT services

- Increased communication/outreach between researchers and central IT

Institution's research/ teaching and learning activities, the overall importance of cyber infrastructure applications and tools will have a minor increase in the next three years.

\subsection{Data Storage and Management}

This section deals with large-scale research data storage systems for real-time use and for archival purposes, as well as facilities, software, and procedures for periodic backup of research data sets. The research use of data storage and management resources at University of Hyderabad is used often by a few personnel only. Researchers at the institution obtain access to data storage and management resources in each of these ways:

- Use resources available to them through governmental or private source/s to a small extent

- Use other campus resources to a small extent

- Use campus central ICT resources \& resources available to them through collaboration/s with other higher-education institution/s to moderate extent.

- Use their own resources or those of their lab/s to a large extent

Data storage and management resources used by researchers at the institution are funded to a moderate extent by funds made available through collaboration/s with other higher-education institution/s and funds awarded to the institution not specifically for the researcher or lab, Research funds awarded to the researcher or lab. A large extent of funding comes from Campus central ICT organization funds. 
Importance of data storage and management is given moderate importance in Research in science and engineering and in Teaching and learning and given minor importance in Research in other disciplines and in Creative activities such as arts, music, etc.

The senior-most ICT leader's detailed knowledge about the research use of Data storage and management resources at the institution as to what resources are available to researchers, who provides these resources, who funds these resources, who is using these resources, what these resources are used for is rated as good. The institution has documented inventory of the Data storage and management resources used for research for all highperformance computing resources.

These would most help the central ICT organization support more effective research use of data storage and management resources:

- Increased funding for central ICT infrastructure

- Increased funding for central ICT services

- Increased communication/outreach between researchers and central IT

Institution's research/ teaching and learning activities, the overall importance of data storage and management resources in the next three years will have a minor increase.

\subsection{Advanced Network Infrastructure}

This section deals with the institution's highperformance networks on campus and its connections to off-campus high-performance networks that support such capabilities as massive data transfers to and from clusters, real-time visualization, and use of remote instrumentation. Off-campus networks used for advanced network infrastructure include regional or university consortia networks. Research use of advanced network infrastructure resources at the institution is used often by many personnel.

Researchers at the institution obtain access to advanced network infrastructure resources in each of these ways:

- Use their own resources or those of their lab/s; Use campus central ICT resources \& resources available to them through collaboration/s with other higher-education institution/s to a moderate extent

- Use other campus resources; Use resources available to them through governmental or private source/s to a small extent.

- Use campus central IT resources to a large extent.
Advanced network infrastructure resources used by researchers at the institution are funded to a large extent by Research funds awarded to the researcher or lab and Funds made available through collaboration/s with other higher-education institution/s; to a moderate extent by Funds awarded to the institution not specifically for the researcher or lab, Campus central ICT organization funds.

Advanced network infrastructure at the institution is given moderate importance in Research in science and engineering and in Teaching and learning; and minor importance in Research in other disciplines, Creative activities such as arts, music, etc. The senior-most ICT leader's detailed knowledge about the research use of Advanced network infrastructure resources at the institution as to what resources are available to researchers, who provides these resources, who funds these resources, who is using these resources, what these resources are used for is rated as good. The institution has documented inventory for some advanced network infrastructure resources.

These would most help the central ICT organization support more effective research use of advanced network infrastructure resources:

- Increased funding for central ICT infrastructure

- Increased involvement of central IT in developing budgets for grants and contracts

- Increased communication/outreach between researchers and central IT

Institution's research/ teaching and learning activities, the overall importance of advanced network infrastructure resources in the next three years will see minor increase.

\subsection{Collaboration within Virtual Communities}

This section deals with facilities and support for teleconferencing, for hosting collaborations with offcampus researchers, and for the operation of remotely located research instrumentation and related devices; and with support for identity management and associated middleware in collaborative research activities. Research use of collaboration within virtual communities at the institution is used often by a few personnel only. Researchers at the institution obtain access to advanced network infrastructure resources in each of these ways:

- Use resources available to them through governmental or private source/s and other campus resources to a small extent.

- Use campus central ICT resources and resources available to them through 
collaboration/s with other higher-education institution/s to a moderate extent

- Use their own resources or those of their lab/s to a large extent.

Collaboration within virtual communities used by researchers at the institution are funded to a large extent by Research funds awarded to the researcher or lab; to a moderate extent by Funds awarded to the institution not specifically for the researcher or lab, Campus central ICT organization funds. And small extent of funding comes from Funds made available through collaboration/s with other higher-education institution/s and other campus funds. The institution has documented inventory of the collaboration within virtual communities resources used for research for all collaboration within virtual communities.

The following are the level of importance of collaboration within virtual communities at the institution:

- Research in science and engineering moderate importance

- Research in other disciplines - minor importance

- $\quad$ Creative activities such as arts, music, etc. moderate importance

- $\quad$ Teaching and learning - minor importance

These would most help the central ICT organization support more effective research use of collaboration within virtual communities' resources:

- Increased funding for central ICT infrastructure

- Increased authority for central IT to enforce standards for resource management

- Increased communication/outreach between researchers and central IT

Institution's research/ teaching and learning activities, the overall importance of collaboration within virtual communities in the next three years is expected to see minor increase.

\subsection{Accountability and Integration}

At University of Hyderabad (UOH), the Campus Network Facility Incharge and the Head of Computer Centre is accountable for and has the authority needed to meet his/her responsibilities for these activities:

- Providing sufficient storage for research data

- $\quad$ Providing security for research systems

- Providing space and environmental support for research ICT resources owned by campus entities other than central ICT

- Providing support services for research ICT systems, such as system administration, identity management, and help desk
- Enforcing the research community's compliance with national regulations regarding privacy of data

- Providing sufficient network bandwidth for research

- Providing sufficient network bandwidth for teaching and learning

- $\quad$ Providing ongoing maintenance and support for ICT resources obtained with one-time research funds

At $\mathrm{UOH}$, effective incentives exist to encourage researchers to partner with the central ICT organization to achieve economies of scale in the use of cyber infrastructure resources and share cyber infrastructure resources with other researchers on campus. The staff of the central ICT Unit feel that they have been very effective at integrating bringing together into a seamless whole a wide variety of human, software, and hardware systems to form a platform for enabling activities in research and in teaching and learning.

\section{ICT practices of the students}

University of Hyderabad has a Total student population of 4746. A survey using Random sampling across different Domains of Study was conducted with a sample size of 495 students as shown in Table 1. The survey aimed to understand how students in University of Hyderabad use ICT in their studies, their attitude towards ICT and to collect their views about the enablers and obstacles in ICT for education.

Table 1. Sample size

\begin{tabular}{|c|c|c|}
\hline $\begin{array}{c}\text { Main Domains of } \\
\text { Study }\end{array}$ & n & \% \\
\hline $\begin{array}{c}\text { Social Sciences } \\
\text { (Masters) }\end{array}$ & 80 & 16.2 \\
\hline $\begin{array}{c}\text { Social Sciences } \\
\text { (Research } \\
\text { Students) }\end{array}$ & 86 & 17.4 \\
\hline $\begin{array}{c}\text { Science and } \\
\text { Technology } \\
\text { (Masters) }\end{array}$ & 81 & 16.4 \\
\hline $\begin{array}{c}\text { Science and } \\
\text { Technology } \\
\text { (Research } \\
\text { Students) }\end{array}$ & 84 & 16.2 \\
\hline $\begin{array}{c}\text { Humanities } \\
\text { (Masters) }\end{array}$ & 80 & 17.0 \\
\hline $\begin{array}{c}\text { Humanities } \\
\text { (Research } \\
\text { Students) }\end{array}$ & 84 & 100 \\
\hline Total & 495 & \\
\hline
\end{tabular}


Home/hostel is the place of most frequent usage of ICT amounting to $67 \%$ of students accessing internet from their residence.

\section{Purpose and degree of ICT usage}

Informative: $60.4 \%$ of the students use ICT very often to find, acquire and use information

Functional: only $33 \%$ of students use and manipulate existing information for educational purposes using existing information (compile lists of books, abstract and summarize books and materials, use accessed information to prepare homework, compare information)

Creating: only $35 \%$ use ICT to compose, compile, produce new information (write papers, drawing, programming, make PowerPoint presentations, give oral presentations, prepare newsletter, create own website, etc.)

Communication: $49 \%$ use ICT to exchange and to transmit information with other students, teachers and others using email and Internet; to join discussion forum and chats.

Collaborative: majority (76\%) do not use Web design tools, multimedia, e-mail, discussion boards, E journals, use technology to simulate research and collaborate with other students (even those situated in different geographical location) and also do not use Web resources and productivity tools to communicate, search for information, and create new products

Overall expertise in handling various types of ICT: $72.8 \%$ of students feel they are average users.

How they learned to use ICT: $46.5 \%$ learned through Trial and error; $30 \%$ learned through guidance from friends and only $16.6 \%$ have formal training in ICT.

Table 2 shows that maximum number of students use computers for academic purpose for 15 to 25 hours in a week.

Table 2. Hours per Week (On an average) of usage of Computer for academic purpose

\begin{tabular}{|l|r|r|r|r|}
\hline & Frequency & Percent & Valid Percent & $\begin{array}{c}\text { Cumulative } \\
\text { Percent }\end{array}$ \\
\hline Valid Missing & 4 & .8 & .8 & .8 \\
\1 $\mathrm{hr}$ & 17 & 3.4 & 3.4 & 4.2 \\
$2.5 \mathrm{hrs}$ & 175 & 35.4 & 35.4 & 39.6 \\
$6.15 \mathrm{hrs}$ & 147 & 29.7 & 29.7 & 69.3 \\
$15.25 \mathrm{hms}$ & 76 & 15.4 & 15.4 & 84.6 \\
$225 \mathrm{hrs}$ & 76 & 15.4 & 15.4 & 100.0 \\
Total & 495 & 100.0 & 100.0 & \\
\hline
\end{tabular}

\section{Attitude and Beliefs towards ICT}

$67.5 \%$ responded that they want to be able to ask questions of experts and relevant people, no matter where they are.

$62.1 \%$ gave negative response that in general, learning with ICT is very time-consuming.

$59.5 \%$ feel that Good access to a tutor requires face to face contact

$78.9 \%$ responded they would like to discuss topics with people from different backgrounds

$77.5 \%$ students prefer reading from a printed text.

$83.3 \%$ think that ICT can improve their learning.

$63.1 \%$ gave a negative response to: Quality information is hard to find on the web (WWW) $45.9 \%$ said they would like to study with a computer, even if it is complicated, $38.1 \%$ gave negative response and $15.4 \%$ were neutral.

$56.7 \%$ like to learn in teams or small groups

$55.8 \%$ gave a negative response to: If a task becomes too difficult, I am likely to drop it

$88.1 \%$ said they would like to share information and ideas with people who have similar interests

$85.1 \%$ think audio and video material can improve their learning

44.4\% have a neutral opinion and $23.1 \%$ have a negative opinion that in online courses, small-group learning may become disorganized

$62.5 \%$ students prefer to learn on their own.

$73.5 \%$ feel ICT allows for effective sharing of experiences

$50.1 \%$ gave a negative response to: preference to study with traditional education methods, $13.5 \%$ were neutral and $34.6 \%$ gave positive response

$46.2 \%$ said if studying with a computer turned out to be too complex, they would like to return to traditional education methods; whereas $36 \%$ gave a negative response and $16.2 \%$ of students gave a neutral response.

$54.3 \%$ disagree to: Learning with ICT requires highly developed study skills.

$70.9 \%$ said they would like to cooperate on a learning task with people from different countries $72.1 \%$ prefer to choose the specific topics to study within a course

$50.3 \%$ said they would like to work with a computer in small groups.

$41.2 \%$ said Learning via the Internet alone is acceptable to me; $48.9 \%$ gave negative response and $9.3 \%$ remained neutral.

$64.1 \%$ like being taught in a classroom setting

$52.7 \%$ feel Computer-based teaching/learning is lacking in 'human' interaction, since there is no face to face contact 


\subsection{Opportunities that might be enhanced by ICT}

$76.5 \%$ feel ICT will help in enabling students to take courses and modules via the Internet from higher education institutions in their own and other countries

93.4 \% feel ICT will help in Enabling students to find out about higher education institutions in their own and other countries before going there to study $91.5 \%$ feel ICT will help in Enabling students to collaborate on academic work with other students in their own and other countries

$90.2 \%$ feel ICT will help in Enabling students to contact professors in their own and other countries for advice on academic questions and problems $84.4 \%$ feel ICT will help in making it easier for students to study abroad by keeping in contact with home

$84.8 \%$ feel ICT will help in enabling students with physical disabilities to access higher education more easily

$78.1 \%$ feel ICT will help in enabling students from less-favoured social backgrounds to access higher education more easily

$82.2 \%$ feel ICT will help in enabling students from remote geographical regions to access higher education more easily

$84.4 \%$ feel ICT will help in enabling students from developing countries to access higher education more easily

$86.4 \%$ feel ICT will help in Developing employability skills such as teamwork, problemsolving, self-learning capability, presentation skills, etc

$71.6 \%$ feel ICT will help in Developing a more autonomous and learner-centered approach in university teaching

$60.7 \%$ feel ICT will help in developing a more collaborative and less individual approach to learning

83.3\% feel ICT will help in Enabling more effective and systematic feed-back from students on quality of learning and teaching

90.9\% feel ICT will help in widening the range of sources of information and knowledge available to students

$76.8 \%$ feel ICT will help in Mobilizing students to participate in university activities within local communities

$87.4 \%$ feel ICT will help in allowing graduates easier access to continuous professional development $83.2 \%$ feel ICT will help in providing more effective and/or frequent feedback to students on their learning progress

\subsection{Advantages of ICT}

In University of Hyderabad ICT is transforming education systems' performance or making a difference in:

Improving conventional teaching and learning processes $-64.2 \%$ agree

Enhancing the quality of your performances $-70.3 \%$ agree

Expanding new skills supply for labour market/ job oriented $-61 \%$ agree

Helped in knowledge transfer $-82.5 \%$ agree

Given more confidence to extend the use of computers to other topics $-80.4 \%$ agree

Increasing motivation to learn $-69.3 \%$ agree

Improved the presentation of material in lessons $74.3 \%$ agree

Makes understanding lessons/assignments more less time consuming- $53.9 \%$ agree

\subsection{Disadvantages of ICT}

$59.5 \%$ students disagree that Using ICT restricts the content of their lessons

$44.9 \%$ disagree, $19.6 \%$ responded neutral and $34.2 \%$ agree that using ICT makes it more difficult to manage the information, causes information overload.

$47 \%$ agree that using ICT has disadvantages of Security concerns (e.g. hacking, viruses) and technology being too complicated $24.7 \%$ responded neutral.

$42.5 \%$ agree that they have lost working time because of irrelevant surfing Data communication; Data communication being too slow or unstable; $26.9 \%$ remained neutral and $29.4 \%$ responded negative.

$48 \%$ disagree and $18 \%$ are neutral regarding the statement that Teachers do not encourage information gathered from the internet, whereas $32.6 \%$ feel that Teachers do not encourage information gathered from the internet.

\section{Major Hindrances/Barriers in using ICT for Educational Purpose}

Following are the major hindrances listed by the students:

- lack of training - $58.5 \%$ students agree

- lack of technical knowledge and support $61.5 \%$ students agree

- $\quad$ limited number of computers $-54.7 \%$ students agree

- limited understanding of how to use ICT for Educational Purpose - 52.3\% students agree

- lack of time $-56.9 \%$ students disagree 


\section{21st Century Skills}

People in the 21 st century live in a technology and media-suffused environment, marked by various characteristics, including: 1) access to an abundance of information, 2) rapid changes in technology tools, and 3 ) the ability to collaborate and make individual contributions on an unprecedented scale. To be effective in the 21st century, citizens and workers must be able to exhibit a range of functional and critical thinking skills related to information, media and technology [2]

$45.5 \%$ of the students in UOH feel they are prepared to some extent in Expertise in field of study, $39.7 \%$ Prepared to some extent in Initiative and self-direction skills. $35.0 \%$ Prepared to some extent Creativity and innovation skills. $41.1 \%$ well prepared Communication and Collaboration skills $38.5 \%$ Prepared to some extent in Information Media and Technology skills $34.8 \%$ Prepared to some extent in Critical thinking and Problem Solving skills $44.7 \%$ Prepared to some extent Understanding of international issues $42.0 \%$ Prepared to some extent Social and cross-cultural skills $41.1 \%$ Prepared to some extent Environmental and social issues 38.7\% Prepared to some extent Overall job readiness; Life and Career Skills 33.7\% Prepared to some extent Productivity and accountability; Leadership and responsibility skills

\section{Top ten visited Sites by users in University Of Hyderabad}

1. http://www.addshare.net/index

With AddShare one can upload files, images, videos, audio and flash for free.

\section{2. http://www.dailymotion.com/in}

The website has the latest music videos, short movies, TV shows, funny and extreme videos. One can Upload, share, and embed videos. Dailymotion is a video sharing service website, headquartered in the 18th arrondissement, Paris, France. According to Comscore, Dailymotion is the second largest video site in the world after YouTube.

3. http://www.nptel.iitm.ac.in/downloads/113 104058/

The website has Educational Videos Lectures, Courses, Classes from National Programme on Technology Enhanced Learning (NPTEL) and Indian Institute of technology (IITs) (Kharagpur, Bombay, Delhi, Chennai, Kanpur, Guwahati),

4. www.mail.google.com/

Gmail: Email from Google

5. www.microsoft.com/

Website provides product information, support, news from Microsoft.

6. http://www.mxn.com/
MXN Ltd., is a fully integrated multimedia and investment firm that acquires, develops and deploys innovative web properties.

7. www.youtube.com/

The Video-sharing website, created by three former PayPal employees in February 2005, on which users can upload, view and share videos

8. http://www.dailymotion.com/in A video sharing website

9. http://fileserve.com/

It facilitates free Online Storage and file upload with 500GB File Storage.

10. http://www.debridmax.com/

DebridMax provides instant download of files, on hosts like Megaupload, Megavideo, Rapidshare, Fileserve and more. It offers a multi-platform hosting completely free.

Number of students visiting Computer Center in a day is around 220 (aprox) and it goes up to 400 in some cases.

\section{Conclusion}

The study shows that capacity building and basic training is required to encourage adoption of Information Communication Technologies for Education (ICT4E). Students who come from rural areas do not have any prior knowledge in using ICT. Information and Library Network (INFLIBNET) is set out to be a major player in promoting scholarly communication among academicians and researchers in India through the UGC-INFONET Digital Library Consortium. INFLIBNET and E-Resources are heavily used by students as each student has access to the University's IGML online library in the department and hostel rooms. Many feel that they don't have to physically visit the library.

Depending on their individual level of interest and skills some students are also making use of Web2.0 and other ICT networks to enhance their knowledge gathering and creation. Hence, a digital divide among the students is also noticed. Many students are members of online groups where they continually share resources and join discussions related to their area of subject interest.

Some students are still juggling between traditional medium and the new medium of learning. Disadvantage being that there is too much information there, filtering the material and also where to get the material becomes a challenge (reliability of material).

There are different categories of students students are more technology savvy now because of the ICT enabling environment that the University of Hyderabad is providing. A lot of them pick up usage of ICT gradually. A lot of learning is participatory. Necessity is the mother in most cases. In the past three years there have been more students 
enthusiastic about picking up ICT skills. Now they realize they cannot do without it.

Each adopter's willingness and ability to adopt an innovation depends on their awareness, interest, evaluation, trial, and adoption. In some cases, it is the access to technology (even prior) to joining the University, which makes them uncomfortable with technology even if they have access now. It could also be lack of initiative - probably they could be called the laggards. Rogers proposes that adopters of any new innovation or idea can be categorized as innovators $(2.5 \%)$, early adopters $(13.5 \%)$, early majority (34\%), late majority (34\%) and laggards $(16 \%)$, based on the mathematically based Bell curve [3]. But even among the people who are using technology, there are some who are very good whereas there are others who will not go beyond the needed features. Students are picking up ICT in different ways. However, there is no gap in the way they use their mobile phones. Communication is all through phones (email/sms/calls) the culture of communication is changing. Research scholar's group is there. There is a community of researchers. A lot of students from abroad come to University of Hyderabad (UOH), students in $\mathrm{UOH}$ are able to access their library (abroad) through them - creating new geographies of learning.

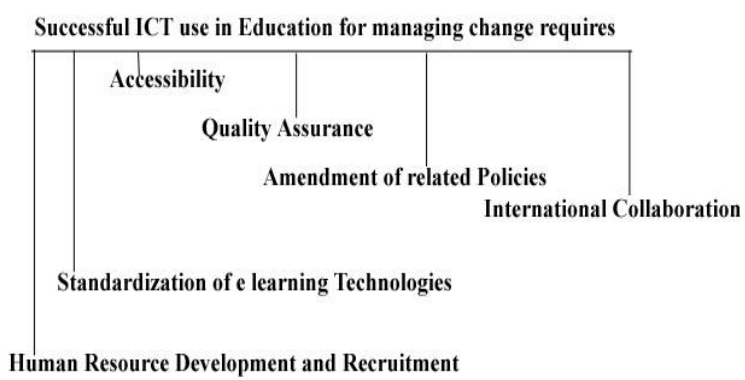

Figure 1. Elements for successful ICT4E management

With education being passed as the constitutional right of every individual in India, ICT with all its advantages needs to be incorporated at all levels of education system, addressing the challenges discussed. ICT4E change agents would involve the policies, process, ICT tools, Knowledge enablers and learners [4]. Hence, successful ICT4E for managing change requires accessibility, quality assurance, amendment of related policies, international collaboration, standardization of learning technologies, human resource development and recruitment. The findings of the study reveal that, students have a low level of ICT use for educational purpose, but hold positive attitudes towards the use of ICT. The findings suggest that ICTs use for educational purposes should be given greater consideration with more capacity building.

\section{References}

[1] Hasenbegovic, J., Gruber, H., Rehrl, M., \& Bauer, J. "The two-fold role of epistemological beliefs in higher education: A review of research about innovations in universities". In P. Tynja"la“, J. Va“limaa, \& G. BoultonLewis (Eds.), Higher education and working lifecollabourations, confrontations and challenges Elsevier, Amsterdam, 2006, pp. 163-176.

[2] The Partnership for 21st Century Skills. http://www.p21.org/documents/P21_Framework_Definitio ns.pdf 2009.

[3] Rogers, E. M. Diffusion of innovations (3rd ed.). New York: Free Press, 1983.

[4] Kamei. M. (2010), 'Information Networks Towards Knowledge Society' International Journal of Electrical Systems and Control (IJESC) Vol. 2, No. 1, January-June 2010, pp. 47-53. 